\title{
The Impact of China's Total Medical Insurance Package Payment Based on Compact County Medical Community and Its Implications for Medical Insurance Funds: Evidence from Y County, China
}

Juming Liu

Tongji Medical University: Tongji Medical College

Yihua Xu ( $\nabla$ xuyihua_6@hotmail.com )

Health commission of Linxiang Distric

\section{Yiqing Yang}

Compact medical community of Lincang District,Lincang,Chin

\section{Kaifu Luo}

compact medical community of Yun connty,Lincang,China

\section{Yangyang Hong}

Tongji Medical University: Tongji Medical College

Huaqin $\mathrm{Hu}$

Tongji Medical University: Tongji Medical College

\section{Menglin Fan}

Tongji Medical University: Tongji Medical College

Yin Luo

Tongji Medical University: Tongji Medical College

Lai Xu

Tongji Medical University: Tongji Medical College

Heyun Lu

Compact medical community of Lincang District

\section{Yan Su}

Compact medical community of Lincnag District

\section{Tianjie Xiao}

Medical Insurance Bureau of Lincang

\section{Ling Shi}

Compact medical community of Yun county

\section{Jiayan Xu}

compact medical conmmunity of Yun county,Lincang,China

\section{Qihua Dong}

Compact medical community of Lincang

Jianxing Wang

Health commission of Linxiang District 


\section{Research}

Keywords: CCMC, NOADP, OIE, IE

Posted Date: December 28th, 2020

DOI: https://doi.org/10.21203/rs.3.rs-133184/v1

License: (c) (i) This work is licensed under a Creative Commons Attribution 4.0 International License. Read Full License 


\section{Abstract}

Background:Due to the irrational structure of medical and health resources, uneven distribution, and low level of grassroots services, traditional medical insurance payment methods in China's underdeveloped areas have not been fully utilized in regulating medical service behaviors and guiding the allocation of medical resources. The medical insurance fund of many regions collapsed, the fund balance rate and compensation rate decreased year by year, and the medical expenses rose rapidly, which seriously affected the enthusiasm of the insured residents. As a results,the sustainable development of the medical insurance fund faced many difficulties and challenges.Based on this, we want to design a medical insurance policy suitable for underdeveloped areas in China to improve the capacity and efficiency of health services and maintain the stability of medical insurance funds.

Methods:Collected medical insurance data of Y County in China from 2018 to 2019. The interruption time series(ITS) was used to evaluate the utilization of medical insurance funds in county-level hospitals, primary health service centers, and hospitals outside the medical community.

Results:Inpatient expenditure(IE) per capita,out-of-pocket inpatient expenditure(OIE) per capita,and medical insurance expenditure (MIE)per capita in county-level hospitals increased by 84.682, 6.564 and 62.302 yuan per month respectively after the reform; Number of annul discharges persons(NOADP) from basic health service centers increased by 36.899 per month after the reform; IE per capita and MIE per capita increased by 18.624 yuan and 15.767 yuan per month on average after the reform; the residents hospitalized outside CCMC decreased by 9.545 per month on average after the reform.

Conclusions:China should further implement the CCMC-based TMIPPM reform to control medical expenses and maintain the stability of medical insurance funds in in more trials.

\section{Contributions To The Literature}

1.In order to maintain the stability of regional medical insurance funds and ease the government's financial pressure, we proposed and implemented a new medical insurance reform plan for China's underdeveloped regions.

2.We implemented this program in China's Y County, a typical remote and underdeveloped area. Therefore, it is possible to observe the impact of the reform on the expenditures of medical insurance funds of different levels of medical institutions in the county, and to observe the changing trend of patients seeking medical care outside the county.

3.The reform has turned the annual balance of the medical insurance fund in $Y$ County from loss to profit, which can provide a reference for the Chinese government to deepen medical reform.

\section{Introduction}

The rapid increase in medical insurance fund expenditure has become, more than ever, a critical obstacle in providing suitable health care services in countries around the world.and as a key method for health care policymakers, the reform of medical insurance payment methods plays an important leverage role in controlling medical costs, increasing the efficiency of fund use, and improving the quality of medical services.[1-3]China is no exception. However, due to the irrational structure of medical and health resources, uneven distribution, and low level of grassroots services, China's traditional medical insurance payment methods have not been fully utilized in regulating medical service behaviors and guiding the allocation of medical resources. The medical insurance fund 
has collapsed, the fund balance rate and compensation rate have declined year by year, and the medical expenses have risen rapidly, causing the sustainable development of the medical insurance fund to face many difficulties and challenges[4-6].In an attempt to provide a solution, China launched the Guiding Opinions on Further Deepening the Reform of Basic Medical Insurance Payment Methods in June 2017, requiring the comprehensive implementation of the reform of medical insurance payment methods based on the third-party advantages of medical insurance, aiming to promote the reform of the medical and health system and the stability of medical insurance funds, While reducing the financial burden of healthcare recipients[7-8].

Y County is located in the southwestern part of Yunnan Province. It was once a provincial-level poverty-stricken county in Yunnan Province, with a backward economic level and low medical and health service capabilities. To solve the above problems, Y County began to explore the integrated management model of county-level hospitals and basic health service centers in 2013, and established the Compact County Medical Community (CCMC) in 2014. The Medical Community, with the County People's Hospital as the core, implements overall management of other county-level hospitals and basic health service centers. At the same time, it has realized the exchange of information among member units and mutual recognition of inspection results, becoming the only national-level medical insurance reform model in Yunnan Province. In order to further control the rapid growth of medical expenses, $Y$ County took the lead in implementing the Total Medical Insurance Package Payment (TMIPP) reform in December 2018 in the country. The principles of the reform are (1) ensure the safety of medical insurance funds (2) package the total medical insurance funds and pay to the medical community (3) balance funds Distributed by the medical community (4) The medical insurance fund overspend will be borne by the CCMC[9-10].The establishment of the CCMC has transformed different medical institutions in $Y$ County from a previous competitive relationship to a symbiotic relationship, which provides favorable conditions for the TMIPP reform in Y County.

According to the TMIPP, the allocation of the medical insurance fund is based on the number of insured persons and fund income in CCMC. The service capacity, service quality, use of the medical insurance fund over the years, and the increase in medical expenses of the member units in the CCMC are considered as evaluation indicators. The annual indicators of CCMC member units are managed and allocated by Y County People's Hospital. After the CCMC's annual financial statements, the balance of the annual indicator use will be retained by CCMC in equal amounts, which can be used for performance rewards, infrastructure construction, etc; if the annual indicator use exceeds the expenditure, the CCMC will bear it.This is to strengthen CCMC's internal management and control, increase the enthusiasm of medical cost control, change passive cost control to active cost control, and promote the transformation of designated medical institutions from scale expansion to intensive development while ensuring that the level of medical services does not decrease.In addition,the CCMC has also established a series of incentive and restraint mechanisms. For example, the medical quality of member units is included in the assessment content, and the assessment is carried out by an expert group. The result is linked to the allocation index of the next year's medical insurance fund, So as to curb member units from conducting bad medical behaviors in order to control MIE.In previous studies, researchers mainly evaluated the practice of medical insurance payment methods such as DRGs and global payment in China[11-13]. However, the reform of the medical insurance system in $Y$ County is a new policy design that has been strongly promoted by the Chinese government.Therefore, there is still a lack of strong evidence to evaluate the effect of CCMC-based TMIPP in China, and there is no report on the impact of the reform on the operation of medical institutions. This research takes $Y$ County as an example, and uses Interrupted Time Series(ITS) to analyze the impact of CCMC-based TMIPP reform on the utilization and expenditure of county-level medical institutions and basic health service centers, as well as the impact on the overall level of inpatient service utilization and expenditure of inpatient institutions outside the CCMC.Provide reference for the further implementation of reform. 


\section{Methods}

\section{Data and samples}

All inpatients in Y County are taken as the research subjects, they can freely choose to seek medical treatment inside and outside the medical community and all of them have participated in medical insurance.Three county-level hospitals and ten basic medical service centers are included in the CCMC in County Y. Taking into account the heterogeneity of different levels of medical institutions, the research will be classified and the hospitalization data outside the medical community will be analyzed at the overall level.Y County is located in the southwestern region of China, with 7 towns and 5 townships under its jurisdiction. In 2018, the permanent population was 466,700, and the residents' participation rate remained above 96\%.[14].The data comes from the national health statistical information network direct reporting system, including the hospitalization records of all insured patients in Y County from 2018 to 2019, a total of 127950 items. Among them, 62,382 data were hospitalizations in county-level hospitals, 21,312 data were hospitalizations in basic health service centers, and 44,256 data were hospitalizations outside the hospital.From the report, extract the relevant data of five evaluation indicators, including ALOS per patient,the number of annual discharged patients,the inpatient expenditure per capita,theOIE per capita,the MIE per capita.The data was initially extracted and sorted by one researcher, and another researcher checked the sorted data with the original data to ensure the accuracy of the data.This patient dataset has various advantages.First of all, this dataset provides the latest patient data in County $\mathrm{Y}$, which is the only national model medical community in Yunnan Province. Secondly, it contains accurate and comprehensive information that can be used to measure health care purposes and medical expenses, including admission and discharge dates and the diseases being treated.

\section{Statistical Analysis}

Y County officially started the TMIPP reform in December 2018. Considering the delay in the implementation of the policy, this study defines the end of December 2018 as the actual policy intervention time point.Since the time span of data collection is from January 2018 to December 2019, the period from January 1, 2018 to December 31, 2018 is the pre-intervention stage, and 2019.01.01-2019.12.31 is the post-intervention stage. The data cycle is divided into 1 month as a cycle. The ITS model is established to estimate the level and trend change of the evaluation index[15-16]. The regression equation is as follows:

$Y_{t}=\beta_{0}+\beta_{1} X_{1}+\beta_{2} X_{2}+\beta_{3} X_{3}+\bigotimes_{t}$

In the equation, $Y_{t}$ is an evaluation index that describes the objective object and is the dependent variable; $\beta_{0}$ is the condition of $Y_{t}$ in the initial test stage, which is a constant term; $X_{1}$ is coded as $1,2,3 \ldots$, which means that the time series corresponds to the observation point in turn;The codes before and after intervention of $X_{2}$ are 0 and 1 respectively, which are the intervention stage of the observation time point; the observation time point before $X_{3}$ intervention is represented by the code 0 , and the observation time point after intervention is represented by $1,2,3 \ldots .$. represents the time series after the intervention, $\square_{t}$ represents random error. $\beta_{1}$ is the slope representing the change trend of the observation object before the intervention, $\beta_{2}$ represents the change level of the observation object during the intervention, $\beta_{3}$ represents the difference between the change trend of the observation object before and after the intervention, and $\beta_{1}+\beta_{3}$ represents the change trend of the observation object after the reform.

The research is carried out in two aspects: (1) Describe the changes in the overall level of operating indicators of medical institutions before and after the reform, and use the paired t test to analyze the overall level differences of related indicators before and after the reform. (2) Fit the segmented regression model based on ordinary least 
squares regression, and use the significance test of the regression coefficient to explain the relevant operating indicators of medical institutions before and after the reform. The Durbin-Waston test is used to test the autocorrelation of dependent variables. If the result does not satisfy that the result is greater than or equal to 1.5 and less than equal to 2.5, it indicates that the dependent variables are not mutually independent, and the least square estimation is used instead[17].Microsoft Excel and IBM SPSS Statistic 25.0 were used for data cleaning and sorting and statistical analysis. If $P<0.05$, the difference is statistically significant.

\section{Results}

\section{Basic situation description}

Table 1 shows the overall level of health insurance fund operation indicators before and after the reform.Compared with before the reform, the average Length of Stay(ALOS)in county-level hospitals and basic health service centers has increased after the reform $(P \otimes 0.001)$; The number of discharged patients(NOADP) has decreased in county-level hospitals and basic health service centers( $P \bigotimes 0.001)$; There is no significant difference in inpatient expenditure(IE) per capita before and after the reform in the overall level of basic health service centers $(P \otimes 0.001)$,but increased in countylevel hospitals $(P \otimes 0.001)$;Both of county-level hospitals and basic health service centers have increased in the out-ofpocket inpatient expenditure(OIE) per capita and medical insurance expenditure(MIE)per capita ( $P \otimes 0.001)$.Compared with before the reform, ALOS outside the CCMC has decreased $(P \otimes 0.001)$, the number of annual discharged patients has no significant difference $(P=0.754)$, the IE per capita and the MIE per capita have decreased $(P \otimes 0.001 ; P=0.025)$, while OIE per capita increased(Pख0.001).

\section{Change trend of inpatient medical insurance fund expenditure index of county-level hospitals before and after reform}

The regression results in Table 2 shows that the ALOS in county-level hospitals only increased before the reform, with an average increase of 0.147 days per month $\otimes \beta_{1}=0.147, P=0.017 \rrbracket$; the IE per capita ,OIE per capita and MIE per capita showed an increasing trend before the reform, with an average monthly increase of 124.997yuan, 23.806 yuan and 92.423 yuan respectively $\otimes \beta_{1}=124.997, P\left[0.001 ; \beta_{2}=23.806, P=0.004 ; \beta_{1}=92.423, P[0.001 \otimes\right.$, The changes in the month of the reform were not statistically significant, but the trends after the reform were $\operatorname{different}\left(\beta_{3}=-40.315, P=0.021 ; \beta_{3}=-17.242, P=0.013 ; \beta_{3}=-30.121, P=0.028\right)$, with an average monthly increase of 84.682yuan, 6.564yuan and 62.302 yuan respectively

$(124.997-40.315=84.682 ; 23.806-17.242=6.564,92 \cdot 423-30.121=62.302)$. There was no statistically significant change in NOADP before and after the reform.

\section{Change trend of inpatient medical insurance fund expenditure index of basic health service centers before and after reform}

The regression results in Table 3 show that ALOS and OIE per capita of basic health service centers have no difference before and after the reform. NOADP has changed from a stable before reform to an upward trend after the reform. the IE per capita and MIE per capita remained stable before the reform, but showed an upward trend after the reform $\left(\beta_{3}=39.832, P=0.005\right)$, with an average monthly increase of 36.898 people(39.832-2.934=36.898).the IE per capita and the MIE per capita had no difference in trends before the reform and in the month of the reform, but there were differences in the trends after the reform $\left(\beta_{3}=15.296, P=0.003 ; \beta_{3}=13.771, P=0.002\right)$, with an average monthly increase 18.624 yuan and 15.767 yuan $(15.296+3.328=18.624 ; 13.771+1.996=15.767)$. 


\section{Change trend of inpatient medical insurance fund expenditure index outside the CCMC centers before and after reform}

The regression results in Table 4 show that ALOS per patient of insured residents hospitalized outside the CCMC showed an increasing trend only before the reform $(\beta 1=-846.585, P=0.041)$; The NOADP before the reform and the month of the reform was not statistically significant, but the trend after the reform was different from that before the reform ( $\beta 2=-13.587, P=0.012)$, with an average monthly decrease of 9.545 persons $(4.042-12.587=-9.545)$; The MIE per capita only decreased by $2,162.817 y u a n(\beta 2=-2162.817, P=0.042)$ in the month of the reform; there were no statistically significant changes in other indicators before and after the reform.

\section{Discussion}

The results of this study enrich the research evidence on the impact of the reform of medical insurance payment methods on the operation of medical institutions. This kind of evaluation of TMIPP reform based on CCMC is very rare in China, especially in areas with underdeveloped economic and medical conditions. As of the end of 2019, The CCMC in Y County Medical Insurance Fund had a total balance of 20.93 million yuan. These funds were allocated by the County People's Hospital to different member units in accordance with policy objectives, with a focus on the development of basic health service centers and public health.The reform has saved a large amount of medical insurance funds for the less affluent Chinese county-level regions, which is worthy of promotion and application.

\section{Discussion on reform effectiveness}

We found that there are differences in the changes in the operational indicators of different levels of medical insurance funds before and after the reform in $Y$ County. The number of people discharged from tertiary hospitals showed no difference before and after the reform, indicating that the inpatient service volume of tertiary hospitals remained stable;There was no difference in the trend of ALOS before and after the reform, while the the IE per capita, OIE per capita, and MIE per capita showed a trend of increase and decrease respectively before and after the reform, indicating that the effect of tertiary hospitals was significant. The possible reason is that excessive drugs, inspections and treatments have been curbed, resulting in effective savings in medical insurance funds. Although the IE per capita have decreased, the total income of county-level hospitals has increased. The principle of keeping the balance of medical insurance funds for use and over-expenditure means that the medical insurance funds have changed from hospital income to hospital costs.County-level hospitals account for $56 \%$ of the annual target of the medical insurance fund. At this time, keeping the medical insurance fund as surplus as possible on the basis of meeting the standards is a key issue for county-level core hospitals to consider.In this regard, the strategy of CCMC in County $Y$ is to change the concept of "treatment-centered" to "people's health-centered", work hard to provide fullcycle health services to residents in the district, and shift the focus of work from disease treatment to health Management, to promote the hospital's transition from "cure for disease" to "save money for disease prevention". Therefore, the strategy of the County People's Hospital is to focus on the optimization and integration of hospital resource allocation, medical treatment, public health business management and assessment, and health business intervention, while actively linking public health institutions to promote the integration of medical services and public health services deeply.

The average hospitalization days and the OIE per capita of basic health service centers have changed steadily before and after the reform, and NOADP has changed from a stable before the reform to an upward trend after the reform.IE per capita and MIE per capita remained stable before the reform, and both showed an upward trend after the reform.It is suggested that the reformed medical insurance reimbursement ratio is more inclined to the residents of 
basic health service centers, and the hospitalization expenses are reduced, which is more attractive to patients. The characteristics of changes in NOADP and the increase in MIE per capita over the same period also indicate that the reform of medical insurance payment methods encourages patients to be hospitalized in basic health service centers, which will promote the flow of medical insurance funds to basic health service centers, thereby strengthening the construction of basic health service centers .Previous studies have shown that due to the limitations of primary medical service conditions and the non-compulsory medical insurance reimbursement, patients are more inclined to seek treatment in tertiary hospitals, resulting in the excessive operation of medical services in large hospitals, and the embarrassing situation of primary hospitals, which not only exacerbates medical insurance ,additional expenses such as consumption of funds, travel and accommodation have also increased the burden on residents for medical treatment. The CCMC's plan is to introduce the management concept of secondary hospitals to the basic health service center, and establish a flexible employment mechanism of "township management for county use, county management for township use, and township management for village use" to promote the cultivation of talents through the flow of talents.At the same time, with county-level hospitals as the link, CCMC promotes the construction of an information platform for high-definition network outpatient clinics, remote consultations in counties and townships, graded diagnosis and treatment, two-way referrals, and regional electronic medical records to further promote the sinking of medical and health resources and the linkage between county and township medical resources.By strengthening the capacity of primary health services, residents will increase their confidence in medical treatment in primary health institutions, and gradually form a medical treatment pattern of "small diseases do not go out of the village, common diseases do not go to the village, and serious diseases do not go out of the county",which can promote fund balance of county people's hospital.The allocation of medical insurance funds is also tilted towards basic health service centers, and the enthusiasm, service capabilities and management level of primary medical institutions are gradually improved.

ALOS for insured patients hospitalized outside the CCMC showed an increasing trend only before the reform,and MIE per capita only decreased in the month of the reform and remained stable after the reform.;NOADP showed no difference in the trend of change before the reform and the month of the reform, but the number showed a downward trend after the reform.Statistics show that OIE used 66.42 million yuanヌAccounted for 29.43\%『and 64.17 million yuan $₫$ Accounted for $26.73 \%$ respectively in $Y$ county in 2018 and 2019. This shows that after the reform, more patients choose to stay in CCMC for hospitalization, which also keeps their medical insurance funds in the medical community. Although some medical insurance funds have been lost,the overall pattern of medical care for patients has been optimized after the reform. The Chinese government requires counties to achieve the goal of $90 \%$ of patients in the county and $65 \%$ of patients in the basic health service center, but CCMC of Y County is still far from the policy requirements. There is an urgent need to implement the family doctor system to standardize the management of patients, strengthen the referral system to leave more patients, and improve medical service capabilities are also the direction that needs to be worked hard in the future.

\section{Comparison with other medical insurance payment methods}

Several major types of medical insurance payment methods widely used in the world include: fee-for-service, global payment, bundle payment, capitation, and Pay-for-performance.At present, most medical institutions in China adopt fee-for-service, which requires medical service providers to record the service items and quantity, and the payer checks the items and quantity and pays the medical expenses at the predetermined price.Therefore, this payment method has the risk of inducing medical demand, lacks a medical cost risk sharing mechanism, and medical cost is difficult to control[18-19],Studies by scholars in the United States have also shown that the false incentives for doctors caused by the payment method of payment by project is one of the important factors that cause the rapid 
growth of medical expenses in the United States[20].In contrast, other payment methods have their own characteristics. The advantage of capitation is that it can effectively control medical expenses, but the disadvantage is that if the medical market lacks competition, the doctor's service enthusiasm may be insufficient, which may reduce services and affect service quality. The main advantage of bundle payment is that it can reasonably control costs, thereby alleviating over-medical treatment, but its shortcomings may not be suitable for complex diseases. For some diseases with insufficient DRGs compensation standards, it will shun critically ill patients and choose high payment standards. Disease phenomenon[21-24].In addition, DRGs also has some practices in China, but we think it is not suitable for China's county-level regions, especially the central and western regions where the economy and medical care are underdeveloped.Relatively speaking, the current stage of medical insurance informatization in these areas and the standardization of hospital information systems are uneven, which leads to inadequate supervision and brings difficulties to the collection of large amounts of data required for DRGs coding.Second, after the implementation of DRGs, doctors may increase their income by over-diagnosing and changing the level of surgery, and cannot really save medical insurance funds; when facing the same price, patients are more likely to prefer county-level hospitals with better medical conditions. Nor can it change the current contradiction between countylevel hospitals and primary health service centers, which runs counter to the reform goals; The total prepaid execution cost is low, and it can effectively control the medical cost, but its disadvantage is that it is difficult to ensure the quality of medical treatment and may cause medical institutions to reject patients[25-28].The performance-based payment method is usually implemented together with other payment methods. The purpose is to control costs while ensuring the quality of medical services. However, its drawback is that performance indicators are difficult to formulate and may induce doctors to ignore medical services other than performance evaluation goals. [29-30].

Compared with the above-mentioned medical insurance payment methods, CCMC-based TMIPP has its own unique advantages.First of all, CCMC takes the county people's hospital as the core and implements unified management of human, financial and material resources for various medical institutions. This has transformed medical institutions at all levels from the previous competitive relationship to a symbiotic relationship, providing favorable conditions for the reform of the total medical insurance package payment method. After the reform, the annual indicators of medical and health institutions at all levels exceed the expenditures, and the medical community shall bear it. This means that the medical insurance fund has changed from medical income to medical costs, forcing medical institutions in the Medical Community to actively control unreasonable medical expenses, reduce the number of transferred patients, promote medical institutions to strengthen self-management, and improve the efficiency of fund use.It is worth noting that the CCMC in County $Y$ included medical quality in the assessment of member units, and the assessment results were linked to the allocation of medical insurance funds, which prevented different medical institutions from shirking patients and reducing service quality. The use of surplus funds is mainly used for the training and introduction of medical technology talents, scientific research, medical equipment, and performance expenditures of grassroots medical staff, so as to gradually improve the medical capabilities and management level of member units, so that the CCMC can develop well and sustainably.

\section{Conclusion}

This study evaluated the impact of the CCMC-based TPMM reform on the utilization and expenditure of inpatient services.According to the results of the study, the reform has maintained the stable development of county-level public hospitals in the short term, and has also promoted the development of basic health service centers. At the same time, it has reduced the number of inpatients outside the resident medical community and saved a large amount of medical insurance funds for the CCMC. From the perspective of this research, the CCMC-based TMPP reform is suitable for county-level areas with underdeveloped economy and medical care. Actively control expenses 
from within the hospital to save medical insurance funds and reduce the burden on the government. It is worthy of promotion and application for Chinese government.

\section{Abbreviations}

\section{TMIPPM}

Total Medical Insurance Package Paymen

\section{CCMC}

Compact County Medical Community

IE

inpatient expenditure

OIE

out-of-pocket inpatient expenditure

MIE

medical insurance expenditure

NOADP

Number of annul discharges persons

ALOS

Average Length of Stay

\section{Declarations}

\section{Ethics approval and consent to participate}

Not applicable

\section{Consent for publication}

Written informed consent for publication was obtained from all participants

\section{Availability of data and materials}

The datasets (Medical record data) generated and analysed for the qualitative study published elsewhere are not publicly available due to maintaining confidentiality of the study participants but are available from the corresponding author on reasonable request.

\section{Competing interests}

The authors have declared that no competing interests exist.

\section{Funding}

the financial support from the the Innovation Research Fund of Huazhong University of Science and Technology (No.5003513021) and the special project for poverty alleviation for temporary cadres directly under Ministry of Education of People's Republic of China (no number).

\section{Authors' contributions}


LJM conceived and designed the study. LJM,XYH, YYQ, LKF, LHY, SY, XTJ, SL,and XJY organized and implemented the reform.DQH and WJX collected the required data.LJM,HHQ,FML, HYY, LY, and XL analyzed the data.LJM wrote the paper.All authors read and approved the final manuscript.

\section{Acknowledgements}

We sincerely thank the Yun County Close Medical Community and the Linxiang District Close Medical Community for their support.

\section{References}

1. Beil H, Haber SG, Giuriceo K, et al.Maryland's Global Hospital Budgets: Impacts on Medicare Cost and Utilization for the First 3 Years. Med Care. 2019;57(6):417-424.

2. Kerner, Á et al.Description Of The Chinese Health Care System After The Health Care Reform Value in Health, Volume 20, Issue 9, A514.

3. Narang AK, Nicholas LH. Out-of-Pocket Spending and Financial Burden Among Medicare Beneficiaries With Cancer. JAMA Oncol. 2017;3(6):757-765.

4. Chen C,Zhang Y,et al.Analysis of cardio-cerebrovascular disease burden on employees covered by Fujian provincial health care in 2005-2014[in Chinese].Chinese Journal of New Drugs and Clinical Remedies.2017;7:428-434.

5. DING J, ZHANG J, CHEN Y,et al.Evaluation and Thinking of the Reform of DRGs-PPS in Public Hospitals in China-Based on Empirical Analysis of Bejing 2011-2018 Pilot Implementation Data[in Chinese].Chinese Journal of Pharmaceuticals.2019;9:1052-1058.

6. Li Y,Wu Q,Xu L,et al.Factors affecting catastrophic health expenditure and impoverishment from medical expenses in China: policy implications of universal health insurance.Bulletin of the World Health Organization.2012;9:664.

7. LIU L,FU X,HU Y ,et al $₫$ Medical insurance payment reform of Chongqing medical consortium[in Chinese].Chinese General Practice.2020;23:795-798.

8. ZHAO Y.Review and upgrade of the goal of medical insurance payment reform[in Chinese].Health Economics Research.2018;2:26-27.

9. Yunxian People's Government Office.Yun County People's Government work Report for 2018.Available from: http://www.ynyx.gov.cn/yxrmzf/xxgk4/zfwj72/zfwj74/158683/index.html.[Accessed October 25, 2018].

10. Yunnan: The "Yun county model" of medical reform has achieved initial results.Available from: http://m.people.cn/n4/2020/0527/c3629-13985140.html.[Accessed May 27, 2020].

11. Zou K,Li HY,Zhou D,et al. The effects of diagnosis-related groups payment on hospital healthcare in China:a systematic review.BMC Health Serv Res.2020;201:112.

12. Zhu XL,Zheng Y,et al.Comparative Study on Global Budget Reform of Regional Health Alliance in China[in Chinese].Chinese Hospital Management.2020;40:21-25.

13. Gong FF,Sun XZ,et al.Practice Research on Health-oriented Medical Insurance Payment Mode Reform.Chinese Hospital Management.2020;40:86-88.

14. Yun County Bureau of Statistics. The 2018 Statistical Bulletin of Yun County.Available from: http://www.ynyx.gov.cn/yxrmzf/zwdt78/tzgg63/305765/index.html.[Accessed May 9, 2019]. 
15. Koskinen H,Mikkola H,Saastamoinen LK.et al.Time Series Analysis on the Impact of Generic Substitution and Reference Pricing on Antipsychotic Costs in Finland.alue Health.2015;18(8):1105-12.

16. Bernal JL,Cummins S,Gasparrini A.Interrupted time series regression for the evaluation of public health interventions:a tutorial.Int J Epidemiol.2017 1;46(1):348-355.

17. Yu SC,Wang Q,Mao F.et al.The design of interrupted time series and its analytic methods. Chinese Journal of Preventive Medicine.2019;8:858-864.

18. Chang F,Ji MY,Zhang JY.The Enlightenment about the Paying Methods of Foreign Medical Insurance[in Chinese].Chinese Journal of Pharmaceuticals,2017;48:936-942.

19. Yao Y,Chen Y,Shi J.Payment Reform of Medical Insurance Payment: Commentary of International and Domestic Research Progress and China's Practice[in Chinese].Chinese Health Economics,2017;6:36-39.

20. GARBER A M,SKINNER J.Is American health care uniquely inefficient?[J]. Journal of economic perspectives, 2008;22(4):27-50.

21. Yuan S,Liu W,Wei F,et al.Impacts of Hospital Payment Based on Diagnosis Related Groups (DRGs) with Global Budget on Resource Use and Quality of Care:A Case Study in China.ran J Public Health.2019;48(2):238-246.

22. Jian W, Lu M, Liu G,et al. Beijing's diagnosis-related group payment reform pilot: Impact on quality of acute myocardial infarction care. Soc Sci Med. $2019 ; 243: 112590$.

23. Meng Z, Ma Y, Song S,et al. Economic Implications of Chinese Diagnosis-Related Group-Based Payment Systems for Critically III Patients in ICUs. Crit Care Med. 2020;48(7):e565-e573.

24. Kealey B, Howie A. ICD-10 is coming an update on medical diagnosis and inpatient procedure coding. Minn Med. 2013;96(11):48-50.

25. Song Z, Ji Y, Safran DG.et al. Health Care Spending, Utilization, and Quality 8 Years into Global Payment. N Engl J Med. 2019 18;381(3):252-263.

26. Agarwal R, Liao JM, Gupta A,et al. The Impact Of Bundled Payment On Health Care Spending, Utilization, And Quality: A Systematic Review. Health Aff (Millwood). 2020 ;39(1):50-57.

27. Kan K, Li SF, Tsai WD. The impact of global budgeting on treatment intensity and outcomes. Int J Health Care Finance Econ. $2014 ; 14(4): 311-37$.

28. Pruitt Z, Robst J, Langland-Orban B,et al. Healthcare costs associated with antiretroviral adherence among medicaid patients. Appl Health Econ Health Policy. 2015 ;13(1):69-80.

29. Kirmani BH, Barnard JB, Mourad F,et al.Mid-term outcomes for Endoscopic versus Open Vein Harvest: a case control study. J Cardiothorac Surg. 2010;5:44.

30. Ryan AM, Krinsky S, Kontopantelis E,et al. Long-term evidence for the effect of pay-for-performance in primary care on mortality in the UK: a population study. Lancet. 2016;388(10041):268-274.

\section{Tables}

Table 1 The overall level of health insurance fund operation indicators before and after the reform 


\begin{tabular}{|c|c|c|c|c|c|c|c|c|c|}
\hline \multirow[t]{3}{*}{ Variable } & \multicolumn{3}{|c|}{ county-level hospitals } & \multicolumn{3}{|c|}{ basic health service centers } & \multicolumn{3}{|c|}{ Outside the CCMC } \\
\hline & Pre- & Post- & $\begin{array}{l}P \\
\text { value }\end{array}$ & & Post- & $\begin{array}{l}P \\
\text { value }\end{array}$ & Pre- & Post- & $\begin{array}{l}P \\
\text { value }\end{array}$ \\
\hline & TMIPP & TMIPP & & TMIPP & TMIPP & & & TMIPP & \\
\hline $\begin{array}{l}\text { ALOS } \\
\text { (day) }\end{array}$ & 7.594 & 7.94 & 0.000 & 5.122 & 5.261 & 0.000 & 10.184 & 8.452 & 0.000 \\
\hline $\begin{array}{l}\text { NOADP } \\
\text { (person) }\end{array}$ & 32339 & 30041 & 0.010 & 14421 & 6908 & 0.004 & 22184 & 22070 & 0.754 \\
\hline $\begin{array}{l}\text { IE per } \\
\text { capita } \\
\text { (yuan) }\end{array}$ & 5137.430 & 5935.73 & 0.000 & 1630.240 & 1638.000 & 0.057 & 6409.068 & 6301.534 & 0.000 \\
\hline $\begin{array}{l}\text { OIE per } \\
\text { capita } \\
\text { (yuan) }\end{array}$ & 1336.330 & 1508.080 & 0.000 & 261.520 & 273.700 & 0.000 & 2389.893 & 2415.823 & 0.000 \\
\hline $\begin{array}{l}\text { MIE per } \\
\text { capita } \\
\text { (yuan) }\end{array}$ & 3616.550 & 4161.090 & 0.000 & 1368.310 & 1384.200 & 0.000 & 3615.232 & 3424.836 & 0.025 \\
\hline
\end{tabular}

Note.TMIPP:the Total Medical Insurance Package Payment; CCMC:Compact County Medical Community; ALOS:Average Length of Stay; NOADP:Number of Annual Discharged Patients;IE:Inpatient Expenditure; OIE:Out-ofpocket Inpatient Expenditure;MIE:medical insurance expenditure.

Table 2 Changes in the expenditure indicators of county-level hospitals before and after the reform

\begin{tabular}{|c|c|c|c|c|c|c|c|c|}
\hline \multirow[t]{2}{*}{ Variable } & \multicolumn{2}{|c|}{$\begin{array}{l}\text { The trend of } \\
\text { Pre-TMIPP }\end{array}$} & \multicolumn{2}{|c|}{ Instant change of TMIPP } & \multicolumn{2}{|c|}{$\begin{array}{l}\text { The trend of } \\
\text { Post-TMIPP }\end{array}$} & \multirow[t]{2}{*}{$R^{2}$} & \multirow[t]{2}{*}{$D-W$} \\
\hline & $\beta_{1}$ & $\begin{array}{l}P \\
\text { value }\end{array}$ & $\beta_{2}$ & $\begin{array}{l}P \\
\text { value }\end{array}$ & $\beta_{3}$ & $P$ value & & \\
\hline ALOS (day) & 0.147 & 0.017 & -1.617 & 0.478 & -0.10 & 0.924 & 0.783 & 1.670 \\
\hline NOADP (person) & -14.850 & 0.550 & -74.804 & 0.728 & 9.462 & 0.760 & 0.361 & 2.375 \\
\hline IE per capita (yuan) & 124.997 & 0.000 & -443.192 & 0.114 & -40.315 & 0.021 & 0.769 & 1.781 \\
\hline OIE per capita (yuan) & 23.806 & 0.004 & -2.016 & 0.978 & -17.242 & 0.013 & 0.626 & 1.589 \\
\hline MIE per capita (yuan) & 92.423 & 0.000 & -371.899 & 0.063 & -30.121 & 0.028 & 0.770 & 1.793 \\
\hline
\end{tabular}

Note.TMIPP:the Total Medical Insurance Package Payment; CCMC:Compact County Medical Community; ALOS:Average Length of Stay; NOADP:Number of Annual Discharged Patients;|E:Inpatient Expenditure; OIE:Out-ofpocket Inpatient Expenditure;MIE:medical insurance expenditure;D-W:Durbin-Waston value. 
Table 3 Changes in the utilization and expenditure indicators of basic health service centers after the reform and inpatient services

\begin{tabular}{|c|c|c|c|c|c|c|c|c|}
\hline \multirow[t]{3}{*}{ Variable } & \multicolumn{2}{|c|}{$\begin{array}{l}\text { The trend of } \\
\text { Pre-TMIPP }\end{array}$} & \multicolumn{2}{|c|}{ Instant change of TMIPP } & \multicolumn{2}{|c|}{$\begin{array}{l}\text { The trend of } \\
\text { Post-TMIPP }\end{array}$} & \multirow[t]{3}{*}{$R^{2}$} & \multirow[t]{3}{*}{$D-W$} \\
\hline & \multirow[t]{2}{*}{$\beta_{1}$} & $P$ & \multirow[t]{2}{*}{$\beta_{2}$} & \multirow{2}{*}{$\begin{array}{l}P \\
\text { value }\end{array}$} & $\beta_{3}$ & $P$ value & & \\
\hline & & value & & & & & & \\
\hline ALOS (day) & -0.003 & 0.932 & -0.019 & 0.960 & 0.003 & 0.924 & 0.949 & 1.968 \\
\hline NOADP (person) & -2.934 & 0.912 & -846.585 & 0.001 & 39.832 & 0.005 & 0.111 & 2.427 \\
\hline IE per capita (yuan) & 3.328 & 0.837 & -155.348 & 0.280 & 15.296 & 0.003 & 0.535 & 1.934 \\
\hline OIE per capita (yuan) & 0.998 & 0.557 & -15.975 & 0.306 & 0.797 & 0.753 & 0.634 & 1.917 \\
\hline MIE per capita (yuan) & 1.996 & 0.892 & -138.003 & 0.306 & 13.771 & 0.002 & 0.634 & 1.949 \\
\hline
\end{tabular}

Note.TMIPP:the Total Medical Insurance Package Payment; CCMC:Compact County Medical Community; ALOS:Average Length of Stay; NOADP:Number of Annual Discharged Patients;IE:Inpatient Expenditure; OIE:Out-ofpocket Inpatient Expenditure;MIE:medical insurance expenditure;D-W:Durbin-Waston value.

Table 4 Trends of inpatient service utilization and expenses of insured patients hospitalized outside the CCMC

\begin{tabular}{|c|c|c|c|c|c|c|c|c|}
\hline \multirow[t]{3}{*}{ Variable } & \multicolumn{2}{|c|}{$\begin{array}{l}\text { The trend of } \\
\text { Pre-TMIPP }\end{array}$} & \multicolumn{2}{|c|}{$\begin{array}{l}\text { Instant change of } \\
\text { TMIPP }\end{array}$} & \multicolumn{2}{|c|}{$\begin{array}{l}\text { The trend of } \\
\text { Post-TMIPP }\end{array}$} & \multirow[t]{3}{*}{$R^{2}$} & \multirow[t]{3}{*}{$D-W$} \\
\hline & \multirow[t]{2}{*}{$\beta_{1}$} & $P$ & \multirow[t]{2}{*}{$\beta_{2}$} & \multirow{2}{*}{$\begin{array}{l}P \\
\text { value }\end{array}$} & $\beta_{3}$ & $P$ value & & \\
\hline & & value & & & & & & \\
\hline ALOS (day) & 0.589 & 0.041 & -5.435 & 0.063 & -0.477 & 0.244 & 0.222 & 1.991 \\
\hline NOADP (person) & 4.042 & 0.863 & 49.315 & 0.830 & -13.587 & 0.012 & 0.132 & 1.894 \\
\hline IE per capita (yuan) & 209.610 & 0.348 & -3309.849 & 0.100 & 161.807 & 0.631 & 0.182 & 1.525 \\
\hline OIE per capita (yuan) & 57.201 & 0.471 & -814.463 & 0.244 & 50.884 & 0.673 & 0.634 & 1.538 \\
\hline $\begin{array}{l}\text { MIE per capita } \\
\text { (yuan) }\end{array}$ & 146.246 & 0.205 & -2162.817 & 0.042 & 46.102 & 0.788 & 0.234 & 1.599 \\
\hline
\end{tabular}

Note.TMIPP:the Total Medical Insurance Package Payment; CCMC:Compact County Medical Community; ALOS:Average Length of Stay; NOADP:Number of Annual Discharged Patients;IE:Inpatient Expenditure; OIE:Out-ofpocket Inpatient Expenditure;MIE:medical insurance expenditure;D-W:Durbin-Waston value.

\section{Supplementary Files}


This is a list of supplementary files associated with this preprint. Click to download.

- Additionalfile1.docx 